\title{
UMA LEITURA DESNORTEADA: A DIFICULDADE NA ALFABETIZAÇÃO CARTOGRÁFICA
}

\section{A DISORIENTED READING: THE DIFFICULTY IN CARTOGRAPHIC LITERACY}

\section{UMA LECTURA DESORIENTADA: LA DIFICULTAD EM LA ALFABETIZACIÓN CARTOGRÁFICA}

\author{
Ana Elisa Milani Baldo Chiachio \\ Graduada em Pedagogia pelas Faculdades Integradas de Jahu \\ Pós Graduada em Psicopedagogia pelas Faculdades Integradas de Jahu \\ e-mail: nemilani@yahoo.com.br \\ Solimar G. M. Bonjardim \\ Doutora em Geografia pela Universidade Federal de Sergipe \\ Coordenadora Núcleo Institucional de Pesquisa e Iniciação Científica - FIJ \\ Docente das Faculdades Integradas de Jahu - Fundação Raul Bauab \\ e-mail: sol_bonjardim@hotmail.com
}

\begin{abstract}
RESUMO
O mundo moderno está a cada momento mais tomado por sofisticadas tecnologias para facilitar a vida, dentre elas destaca-se as relacionadas à localização e conhecimento do espaço. A população está tão dependente da fala dos mesmos que qualquer necessidade de interpretar os próprios dados causa desespero e dificuldades. Ao se deparar com tal realidade adultos e adolescentes vêm sendo chamados de analfabetos geográficos. Diante disso, o presente artigo tem o objetivo de analisar, através da pesquisa bibliográfica, a modernização geográfica, assim como seus reflexos no desenvolvimento da alfabetização cartográfica no Ensino Fundamental I. Para tanto, apresenta-se alguns pressupostos pedagógicos para ensinar sobre localização, além da necessidade de considerar a criação de elos entre conhecimentos concretos e abstratos para que uma alfabetização cartográfica seja bem sucedida e que se diminua o número de pessoas que desconhecem o processo de localização no espaço.
\end{abstract}

Palavras-Chave: Alfabetização-Espacial. Cartografia. Ensino-Aprendizagem.

\section{ABSTRACT}

The modern world has been taken by sophisticated Technologies to make life easier, among them, the ones connected to location and space knowledge are highlighted. The population is so dependent on their speaking that any need of interpreting the simple data may cause desperation and difficulties. Facing this reality, adults and adolescents have been called of geographic illiterates. Then this article has as its goal the analysis of geographic modernization through bibliographic research and its reflection on the development of cartographic literacy on Elementary School as well. Therefore, some pedagogical presuppositions are shown to teach about location and also the need of considering the creation of links between factual and abstract knowledge to make a cartographic literacy successful and to reduce the quantity of people who don't know the process of location in space. 
Keywords: Space-Literacy. Cartography. Teaching-Learning.

\section{RESUMEN}

El mundo moderno está cada vez más tomado por tecnologías sofisticadas para facilitar la vida, entre ellas resaltan las relacionadas a la ubicación y conocimiento del espacio. La población está tan dependiente del discurso de estas tecnologías que cualquier necesidad de interpretar sus propios dados les causa desesperación y dificultades a las personas. Frente a tal realidad, adultos y adolescentes han sido llamados de analfabetos geográficos. Ante ello, este artículo tiene como meta analizar, a través de la busca bibliográfica, la modernización geográfica, así como sus reflejos en el desarrollo de la alfabetización cartográfica en la Escuela Primaria. Para eso, se presenta algunos supuestos pedagógicos para enseñar sobre la ubicación y también sobre la necesidad de considerar la constitución de puntos de conexión entre los conocimientos concretos y abstractos para que una alfabetización cartográfica sea bien sucedida y que el número de personas que desconocen el proceso de ubicación en el espacio sea disminuido.

Palabras Claves: Alfabetización-Espacial. Cartografía. Enseñanza-Aprendizaje.

\section{INTRODUÇÃO}

$\mathrm{Na}$ atualidade inúmeras discussões e pesquisas relatam problemas do analfabetismo tanto no Brasil quanto em várias regiões do mundo. Nas mesmas são apresentadas taxas de analfabetismo, motivos, realidades e, também, conceitos correlacionados como o de analfabetismo funcional. Esse conceito relaciona-se a pessoa que é alfabetizada, mas tem dificuldade em interpretar e utilizar a leitura/escrita em seu cotidiano. Segundo Ribeiro (1997), o alfabetizado absoluto transpassa o nível escolar, são indivíduos desenvolvidos no contexto sociocultural, capazes de utilizar a interpretação em sua plenitude. De acordo com dados do IBGE sobre analfabetismo, o Brasil a cada ano diminui o número de pessoas analfabetas, e, na contramão, aumenta o número de analfabetos funcional, isto é, de pessoas que não conseguem ler com total qualidade, interpretar o que está sendo posto e que, ao se afastar do nível escolar, não compreende símbolos, críticas, imagens e/ou números a ela apresentados.

Ao observar as discussões atuais sobre o assunto, outros conceitos são utilizados para abarcar áreas específicas desse universo do analfabetismo funcional. Um conceito pouco discutido é o analfabetismo espacial ou geográfico ou cartográfico. Esse conceito pode ser aplicado quando uma pessoa alfabetizada é incapaz de ler o espaço e as paisagens ao seu redor, de compreender símbolos e significados, e que ao se deparar com um mapa ou instruções simples de pontos cardeais e lateralidade sente-se inapto a interpretá-los. São pessoas que apresentam o nível da representação de imagens e do situar-se no local deficitário. 
Essa inabilidade causa problemas tanto para pessoas, quanto para empresas e países. Grande parcela da sociedade, apresenta objeções ao retirar informações de materiais cartográficos, tornando-se mais comum a cada ano. É possível observar as consequências dessa dificuldade em atividades rotineiras como o deslocamento em um local desconhecido com o auxílio de um GPS, a interpretação de um dado meteorológico em jornais e até mesmo na distinção da lateralidade. Erros em notícias de jornal, internet ou documentos oficiais de informação acontecem em todos os lugares, prejudicando o discernimento do grande público, impactando na economia e na vida social. Além de refletir diretamente na educação, na discussão geográfica, espacial e, especificamente, na alfabetização cartográfica.

A situação apresentada vem sendo observada desde o século passado, embora tenham ocorrido diversas mudanças no material e nas leis que sugestione alterações na prática docente, dentro das salas de aula ainda são encontrados diversos problemas. Autores como Penteado (2008), Castellar (2005) e Callai (2005) discutem essa problemática situando-a na base de toda a educação proveniente do ensino fundamental. Para elas a criança deve iniciar a alfabetização geográfica no ensino fundamental aproximando aprendizado, espaço vivido, representação do corpo, conhecimento e a percepção da casa, do bairro e dos caminhos percorridos.

A partir disso, fica evidente a necessidade de se expor como estudiosos da área se posicionam em relação ao aprendizado tradicional e quais são suas sugestões de mudanças para uma educação global. De acordo com Callai (2005), a educação no Brasil passa constantemente por muitas atualizações, seja por força política ou por necessidade científica, todavia ainda são necessárias novas discussões para trabalhar com problemas como o apresentado acima. Provavelmente a sociedade atual exige mudanças profundas para combater este tipo de analfabetismo funcional.

Diante desse cenário, o presente trabalho analisa a renovação da geografia e seus reflexos para o desenvolvimento da alfabetização cartográfica, discutindo a modernização de tal aprendizado, o contexto atual e os métodos de ensino. Para isso, este artigo segue uma abordagem qualitativa e desenvolvido a partir de fontes secundárias, encontradas por meio de pesquisas bibliográficas e discutidos para a compreensão do tema proposto.

\section{GEOGRAFIA E CARTOGRAFIA}


O ensino da Geografia tem passado por muitas transformações ao longo das últimas décadas, como esclarece os Parâmetros Curriculares Nacionais - PCN (BRASIL, 1997). Essa ciência, na raiz de sua formação, é classificada como a Geografia Tradicional permeada pela descrição do espaço, envolvendo o espaço físico (relevo, hidrografia, vegetação, etc.) e a vivência de seus habitantes, contudo sem a vinculação das relações pessoais. Depois passa à Geografia trabalhada na modernidade, no contexto das guerras e revoluções os estudos geográficos passam a ser comandados pelas análises da realidade mundial pelo uso de tecnologias. Posteriormente, com a necessidade de entender as relações complexas na década de oitenta, a ciência geográfica caminha para explicações econômicas e trabalhistas do mundo inadequadas para a etapa escolar devido a sua complexidade. Todavia, o livro didático conserva a linha tradicional, descritiva e descontextualizada. Até esse momento a produção geográfica acadêmica ignorava a dimensão subjetiva e efetiva da relação homem-natureza.

Nas últimas décadas, com as novas discussões sobre essa ciência e seu desenvolvimento pleno transformado em uma nova abordagem, a Geografia englobou a dimensão subjetiva e efetiva, traduzida nos estudos sobre paisagens afetivas, modo de vida, espaço vivido, relações cotidianas, singularidade e particularidade dos lugares, enfatizando, assim, a relação social com a natureza, discutindo a subjetividade e singularidade das relações homem-natureza, na qual a chave da aprendizagem passa a ser o aluno e seus conhecimentos prévios.

Desse modo, os conteúdos escolares devem estar totalmente alicerçados dentro de símbolos e significantes para o discente, fazendo com que seus estudos passem a ter um sentimento de concretude, facilitando a aprendizagem principalmente entre o abstrato e a representação concreta do mesmo (BRASIL, 1997). Entretanto, devido as mudanças metodológicas e conceituais da geografia, o ensino apresenta-se deficitário, sem uma base metodológica única.

Atualmente, é incabível um fazer pedagógico e geográfico repleto de memorização e dados desconectados da realidade da criança. De acordo com Castellar (2000, p. 30-31) "essa concepção é muitas vezes incompatível com o desenvolvimento do pensamento da maioria das crianças, pois não considera que toda criança tem o seu próprio ritmo". A transmissão de verdades absolutas, a negligência com as particularidades, a não valorização do erro como meio de aprendizagem e a visão de que a Geografia não contribui para um ensino multi, inter e transdisciplinar deveria ter sido deixada no passado, e se reinventado com o avanço das 
descobertas pedagógicas, renovando-se através da aliança com o lúdico e as novas tecnologias, dentre outras infinitas possibilidades.

Contudo, o processo ainda está em curso, para que essa modernização ocorra faz-se necessário a quebra de pressupostos que os anos foram camuflando. Pré-conceitos que hoje estão instaurados nos educandos e nas famílias dos mesmos, passados como tradição entre as gerações. Penteado (2008) compreende que o público em geral enxerga a geografia como contornos de espaços estáticos e imutáveis, denominações e termos desnecessários ao conhecimento como a relação entre estados e capitais, listas com nomenclaturas de acidentes geográficos, extensão de rios, altitudes de planícies e planaltos e temperaturas máximas e mínimas em diferentes locais da Terra. A autora completa que esse tipo de pensamento precisa ser modificado e sua prolongada permanência se deve ao pensamento geral. Lacoste (1998) resume tal discussão ao dizer que diante de todas as disciplinas trabalhadas no currículo escolar, a Geografia é a única que se apresenta sem utilidade fora dos muros da escola, visto que tal conteúdo, infelizmente, é encarado como apenas uma nota no boletim, utilizada apenas na sistematização do ensino. Por que? Por que quanto mais distante da realidade vivida, mais inútil é o conhecimento.

Na escola, como afirma Castellar (2005), as discussões distorcem o contexto, pois o ensino sistematizado é direcionado para ler, escrever e contar, distanciando, nesse processo, o dia a dia do aluno, e esquecendo que aprender a ler o mundo faz parte da alfabetização. Nessa visão, Callai (2005, p. 229), aponta que a Geografia ainda é caracterizada pela “enumeração de dados geográficos e quebra de espaços fragmentados, em geral, opera questões desconexas" no lugar de considerar o complexo espaço geográfico como um todo. Para a autora é necessário aprender a pensar e a sentir o espaço, para construir a noção de espaço socialmente ocupado conectado com o todo.

No meio desse pensamento, tem-se observado um esforço por parte de educadores e envolvidos com tal modernização, a preocupação com este paradigma:

(...) é no ensinar a fazer a leitura do mundo e, portanto, no como ocorre esse processo de aprendizagem que se poderia retirar da geografia esse rótulo de matéria decorativa. Mas qual é o significado dessa leitura para os alunos do ensino básico? Saber ler uma informação do espaço vivido significa saber explorar os elementos naturais e construídos presentes na paisagem, não se atendo apenas à percepção das formas, mas sim chegando ao seu significado. (CASTELLAR, 2005, p. 212).

E complementa Callai, (2005, p. 231): 
Para romper com a prática tradicional da sala de aula, não adianta apenas a vontade do professor. É preciso que haja concepções teórico metodológicas capazes de permitir o reconhecimento do saber do outro, a capacidade de ler o mundo da vida e reconhecer a sua dinamicidade, superando o que está posto como verdade absoluta. É preciso trabalhar com a possibilidade de encontrar formas de compreender o mundo, produzindo um conhecimento que é legítimo.

Desse modo, a batalha da reinvenção e a renovação de todo o processo histórico do ensino geográfico instalou-se. De acordo com os PCN's (BRASIL, 1997, p. 74) a Geografia moderna é o estudo das "relações entre o processo histórico que regula a formação das sociedades humanas e o funcionamento da natureza, por meio da leitura do espaço geográfico e da paisagem." O ensino da geografia atual que necessita ser aplicado, segundo os PCN's (BRASIL, 1997), baseia-se no estudo das relações entre o processo histórico e a natureza que nos rodeia. O objetivo deste processo de ensino-aprendizagem deve ser a formação de um indivíduo crítico que consiga criar estratégias para a compreensão do espaço geográfico, ou seja, compreenda as informações contidas na organização da paisagem a qual está inserido, tornando-se um leitor que interpreta as paisagens, os espaços e compreende as representações cartográficas, ou seja, um aluno que se tornará um adulto alfabetizado espacialmente.

Desta maneira, segundo o CENP (SÃO PAULO, 1989), entender o espaço produzido é saber identificar as relações do homem com a produção, circulação, distribuição e consumo de produtos, relações que materializam essa organização social.

No ensino fundamental, de acordo com os PCN's (BRASIL, 1997), é exatamente quando esse ensino deve iniciar-se, pois evidenciar o lugar que permeia a vida desta criança, gera a percepção do que está a sua volta. Essa percepção se estende/permeia a medida que tal relação se torna mais complexa a partir do seu próprio espaço concreto. Callai (2005) afirma que o desenvolvimento da criança que segue essa linha de aprendizado e é estimulada pelo desafio, resulta em um aumento de sua percepção pelo o que a rodeia, estimulando a criança a buscar mais conhecimento, tornando-a curiosa.

Passini (1994), por sua vez, atenta para o fato de que a leitura dentro da geografia, de forma adequada possibilita o desenvolvimento da autonomia do leitor. Pois "a capacidade de visualização da organização espacial é importante como conhecimento para uma participação responsável, consciente e a possibilidade de propor mudanças alternativas.” (1994, p.11); Ou seja "A leitura de mapas não se resume, portanto, em localizar um rio, uma cidade, tampouco dizer o que há em determinado lugar.” (1994, p.26). A leitura geográfica transpassa o visível, 
concentrando-se na organização, dinâmica e relações dos seres humanos com o espaço. É saber ver os significados da paisagem, é a criança compreender o que está acontecendo ao seu redor.

Nota-se então, que a Geografia atual necessita de uma autonomia maior para que seus educandos desenvolvam tal noção do espaço que pode ser modificado por si ou pelos outros que o circunda. Callai (2000), em concordância com Cavalcanti (2005), frisa em seus estudos, que independe do material utilizado, o foco da alfabetização geográfica deve ser na conceituação do lugar vivenciado, e que por sua vez, este deve significar para a criança, e não ser apenas um conceito solto dentro de tantos outros que devem ser memorizados, fazendo do discente o sujeito e agente de sua aprendizagem.

Desse modo, a alfabetização geográfica não deve ocorrer de maneira isolada dentro do ensino fundamental, mas sim se materializar em outras disciplinas, ou seja, permitir a interdisciplinaridade. Como exemplo de uma situação-problema é o trabalho na Matemática com o perímetro da sala de aula do educando através de sua representação em escalas, ou ainda, em Língua Portuguesa a professora fazer uma interpretação de texto sobre dados meteorológicos, ou até mesmo que trabalhar locais distintos e posteriormente sua localização no globo terrestre, entre outras.

Nesse contexto, a Geografia alia-se a Cartografia, que é uma linguagem geográfica e caracteriza-se como a ciência da representação da realidade, conjunto de estudos e operações científicas (LUNKES; MARTINS, s.d.) para a construção de mapas. Além disso, nos PCN's (BRASIL, 1997) a Cartografia é o estudo da visão que se obtém do espaço, é conseguir se localizar, interpretar pontos de referência e sua lateralidade, saber seu lugar no espaço habitado, conseguir visualizar o mundo à sua volta em diferentes patamares e contextos. Assim, nota-se sua importância na aprendizagem, não apenas para a interpretação de um desenho qualquer, mas a aprendizagem da Cartografia dentro da Geografia que ultrapassa as fronteiras de um papel, é desenvolver a visão abstrata, é a criança aprender a sentir o espaço geográfico.

De tal modo, o panorama de uma alfabetização espacial deve considerar muito além do observar um mapa, alfabetizar em Geografia "significa criar condições para que a criança leia o espaço vivido" (CASTELLAR, 2000, p. 30). Para a criança compreender o que a permeia precisa inúmeros processos, passando pela observação, identificação, análise, entendimento para enfim alcançar uma representação concreta, podendo ser esta, um esboço de seu quarto utilizando símbolos pessoais, por exemplo. Independentemente do que será retratado, o educando precisa dessa assimilação que não ocorre de maneira mecânica e precisa ser mediada. 
Penteado (2008, p. 43) apresenta que este mediador "pode vir a ser tanto um agente facilitador e catalisador, quanto um agente que o retarda, dificulta ou inibe". Essa mediação pode ser nomeada como a metodologia aplicada dentro de uma alfabetização cartográfica.

Contudo, aqui se instala a maior dificuldade enfrentada pelas séries iniciais, tanto para os professores quanto para os alunos, tal alfabetização na maioria das vezes é enfrentada como algo estático, repleta de conteúdos desconexos que podem e devem ser ensinados de maneira tradicional, sem considerar os fatores intrínsecos e extrínsecos (PENTEADO, 2008). Contrariando o pensamento da autora, Callai (2005, p.233), afirma que "ao caminhar, correr, brincar, a criança está interagindo com o espaço que é social, ampliando seu mundo e reconhecendo a sua complexidade" falta apenas o professor realizar a conexão entre as atividades apresentadas e a alfabetização cartográfica. Ela afirma ainda que não há uma regra formada para esse ensino, mas o mesmo deve ser pautado no diálogo e no estímulo pela curiosidade, não apenas na cópia de diferentes escritas.

Por sua vez, é possível verificar que o bom desempenho na alfabetização cartográfica oferece valorosos benefícios para os indivíduos e para sociedade. Passini (1994) aponta que o “conhecimento do espaço é o caminho para a autonomia político-financeira e que um dos instrumentos para este conhecimento é o mapa" (p.15). A autora ainda afirma, que tal habilidade pode ser facilitadora no exercício da cidadania, já que saber ler um mapa é um saber universal, assim como muitas ações em sociedade, dessa forma verifica-se mais uma vez a importância desta alfabetização, que atualmente apresenta-se estratificada e desconectada na esfera social, assim como muitos conceitos sistemáticos do ensino, formando crianças, jovens e adultos analfabetos espaciais

\section{MÉTODOS DE ENSINO}

Segundo Cavalcanti (2005) as formulações de Vygotsky (1993), demonstram o complexo processo de formação de conceitos que ajudariam os educadores a descobrir o caminho para atingir os objetivos do desenvolvimento do educando, inclusive na matéria de Geografia. O que se percebe em sua análise, é que existe uma variável nos alunos relacionada às suas práticas sociais cotidianas, que devem ser levadas em consideração, pois essas é que lhes conferem a noção de dimensão espacial. As orientações metodológicas que consideram esses aspectos são atribuídas a uma visão socioconstrutivista do ensino. Em que, a maior relevância, é o fato do aluno ser o construtor do seu próprio conhecimento. 
A proposta socioconstrutivista, a grosso modo, caracteriza-se pela mediação simbólica dos conteúdos escolares aos objetos reais do seu conhecimento, em que se pode identificar melhor seu objetivo. Para Cavalcanti (2002, p. 31-32):

\begin{abstract}
A perspectiva socioconstrutivista (...) concebe o ensino como uma intervenção intencional nos processos intelectuais, sociais e afetivos do aluno, buscando sua relação consciente e ativa com os objetos de conhecimento (...). Esse entendimento implica, resumidamente, afirmar que o objetivo maior do ensino é a construção do conhecimento pelo aluno, de modo que todas as ações devem estar voltadas para sua eficácia do ponto de vista dos resultados no conhecimento e desenvolvimento do aluno. Tais ações devem pôr o aluno, sujeito do processo, em atividade diante do meio externo, o qual deve ser 'inserido' no processo como objeto de conhecimento, ou seja, o aluno deve ter com esse meio (que são os conteúdos escolares) uma relação ativa, uma espécie de desafio que o leve a um desejo de conhecê-lo.
\end{abstract}

Callai (2005) ressalta que o importante é estimular a compreensão de saber ler o espaço, buscando no momento da alfabetização que a criança tenha a capacidade de ler e compreender o que as paisagens aparentam ser, assim como desenvolver a capacidade de ler seus significados. Ou seja, é necessário que o professor estimule o aluno a ler o espaço, ao invés de somente ditar para um aluno, ou ler um livro, ou responder perguntas a partir de um texto (CALLAI, 2005). No entanto, a autora observa que não existe uma regra para aprender a ler o espaço. Segundo ela, pedagogicamente, é necessário que se estabeleça o exercício do diálogo com os outros, com o espaço, com a natureza e com a sociedade. Assim, formando a raiz do entendimento espacial, seu funcionamento e relações.

Paralelamente a essa visão, Cavalcanti (2005, p.201) alerta para que o professor aguce a sensibilidade para identificar os significados que os educandos demonstram dos conceitos científicos que se aplica em aula, sempre relacionando o cotidiano com o científico na construção do conhecimento. Este deve ser orientado pelo fato de que o raciocínio geográfico será construído pelo aluno, se for trabalhado como um processo que parte do dele e nele se desenvolve, a alfabetização acontece. Sempre considerando o papel do conhecimento científico e do professor como auxiliares de todo o processo, principalmente nas construções iniciais.

Ao mencionou a importância dos conceitos científicos, pode-se esclarecer suas características e importância que, de acordo com Cavalcanti (2005), são essenciais para todo o contexto. Para a formação de conceitos, existe a necessidade do desenvolvimento do modo de pensar geográfico mais abrangente e abstrato. Os autores já mencionados concordam que para 
a alfabetização e construção do conhecimento geográfico é primordial o entendimento do abstrato, do que é real - concreto (o que a criança vê) e do que é representativo - abstrato (um desenho). Nesse ensino alguns conceitos são mais gerais, como natureza, território, paisagem, região, além de outros essenciais do ponto de vista espacial, como ambiente, cidade, identidade cultural, degradação ambiental, entre outros que compõe a linguagem geográfica.

Morais e Lastória (2011) alertam para o processo de alfabetização cartográfica, que de fato não se conclui em somente ler mapas, mas também construir outros conceitos como: visão vertical e oblíqua; lateralidade e orientação; proporção e noções de escala e legenda. É significativo fazer referência a esses conceitos, com o intuito de orientar à importância de definir suas especificidades no processo de aprendizado cartográfico.

Quando este tipo de processo é analisado mais afundo, é possível identificar e até ressaltar a importância de tais conceitos terem sua base fixada já na educação infantil, através de atividades simples e rotineiras de psicomotricidade, como uma brincadeira no parque de areia, um simples esconde-esconde ou até mesmo um "vivo ou morto", dentre inúmeras outras maneiras, ainda que lúdicas, que desenvolvam o educando, permitindo sua apreensão destes conhecimentos. Já no caso do conceito de visão oblíqua e vertical, observa-se, por sua vez, como um desafio para crianças dos primeiros e segundos anos do ensino fundamental. Isto ocorre pelo grau de abstração e a necessidade da adoção de outro ponto de vista que não seja real.

O conceito de imagem tridimensional e bidimensional, onde o primeiro é o espaço de vivência da criança e o segundo o papel, existe a necessidade de utilizar uma metodologia de trabalhar primeiro com maquetes para facilitar a compreensão da criança. Em relação à proporção de escala, apesar de ser abordada no quarto e quinto ano, ela será melhor compreendida nos anos finais do ensino fundamental, pela sua relação com a matemática, artes e ciências da natureza. Mais uma vez aqui, faz-se uma pausa para enfatizar a importância da geografia não ser trabalhada isoladamente dentro do currículo escolar.

O domínio dos conceitos podem ajudar muito no aprendizado, no entanto, como analisa Cavalcanti (2005), o conteúdo geográfico para se tornar ferramenta do pensamento do aluno, exige muita comunicação em sala de aula, buscando generalizações de conceitos, entendimento de sistemas conceituais, e que busque outras dimensões dos aspectos humanos, como o emocional, o social, e não apenas cognitiva e racional. 
Assim, existem jogos e tecnologias como aliados desta prática educacional. As fotos de satélite, os sites de localização espacial em tempo real, entre outros, são algumas dentre as infinitas possibilidades de se trabalhar a verticalização da imagem dentro de sala. Os PCNs (BRASIL, 1997) ainda, indicam a necessidade deste uso, já que a imagem aérea mostra um ponto de vista diferente dos mesmos espaços, que podem, por exemplo, já ser conhecido da criança, como o entorno do colégio. Vale acrescentar que diferentes visões de um mesmo lugar faz o educando desenvolver o raciocínio abstrato, primordial para a alfabetização espacial.

Por sua vez, em relação aos jogos, busca-se trabalhar a base dos conceitos necessários ao conteúdo, que serão ministrados mais tarde, com o avançar do educando na grade escolar. Conceitos como lateralidade, memória, noções de grandeza e proporção são opções que podem ser aperfeiçoadas com um simples jogo de quebra-cabeças, por exemplo. É o que nos mostra Silva quando afirma que o jogo:

[...] confere ao aluno um papel ativo na construção dos novos conhecimentos, pois permite a interação com o objeto a ser conhecido incentivando a troca de coordenação de ideias e hipóteses diferentes, além de propiciar conflitos, desequilíbrios e a construção de novos conhecimentos fazendo com que o aluno aprenda o fazer, o relacionar, o constatar, o comparar, o construir e o questionar (SILVA, 2006, p. 143).

Penteado (2008) concorda com Silva (2006), quando nos diz que em uma metodologia mais eficaz, ao se trabalhar conceitos como bairro, cidade, estado ou país, "inicialmente seria importante proporcionar à criança a oportunidade de lidar com o espaço dominável por ela, através, por exemplo, de atividades lúdicas" (2008, p. 37). Trazendo experiências distintas aos discentes, sendo estas, por sua vez, vivenciadas e registradas por meio de um desenho, redações sobre os caminhos e seus sentimentos, e assim consecutivamente, incorporando tais representações e instigando o desenvolvimento de habilidades que são pouco incentivadas, além, é claro, de tornar palpável conceitos gerais como "dentro", "fora", "em cima", "em baixo" e posteriormente conceitos geográficos como "limites" e "fronteiras".

Cabe aqui então, uma última reflexão sobre todo este trabalho de métodos: apesar da busca incessante pela modernização do estudo, para que acompanhe-se a demanda de alunos que vem compondo as salas de aulas das mais diversas estratificações sociais, certos postulados são atemporais, e devem embasar acima de tudo o processo de ensino-aprendizagem independentemente da disciplina que se ministrar, segundo Penteado (2008): 
- A aprendizagem faz-se de maneira constante, partindo do todo para as partes e vice-versa, em todos os momentos de seu processo;

- Para a criança, se faz concreto aquilo que ele acredita ser, sendo assim, considerar "concreto" apenas o que é palpável nos leva a cometer erros durante tal processo;

- Pode se considerar "próximo" ao educando, aquilo que faz parte de sua realidade devido à importância que lhe é dada.

Sendo assim, nota-se que dentro de qualquer prática de "ensinagem" não é possível abarcar o todo, ou seja, "a globalização da observação e estudo" (PENTEADO, 2008, p. 38), e ao mesmo tempo considerar todos os detalhes intrínsecos em tais conhecimentos. Desta maneira, cabe ao mediador direcionar o olhar de seu sujeito, tornando-o dinâmico e capaz de fazer as associações necessárias de seus conhecimentos, de maneira geral, para o entendimento do novo, para desenvolver e construir sua alfabetização espacial.

\section{CONSIDERAÇÕES FINAIS}

A partir do que discutiu acima, evidenciou-se a importância da alfabetização espacial ou cartográfica para a sociedade atual, que cada vez mais vem requerendo conexões entre conhecimentos significantes, abstratos e concretos, criando cidadãos mais críticos, capazes de ler geograficamente o mundo, a partir de conceitos bem formados, com análises mais rigorosas, imersas no exercício constante da curiosidade. Formando, assim, um cidadão em evolução constante. Não apenas conceitos isolados, que são impostos e incorporados pelos discentes de maneira evasiva.

Para tanto vê-se a necessidade de um aprimoramento das técnicas e metodologias empregadas para se atingir o objetivo, do mesmo modo como um investimento maior na formação dos professores, acompanhado de um olhar crítico e sensível para os livros didáticos, sem deixar ocorrer a generalização do processo de ensino-aprendizagem; mas sim levar em consideração as peculiaridades e autonomia de cada um, enxergando o discente como o ser completo e complexo que ele é.

Considera-se então, que o quadro atual não se demonstra favorável a um bom desempenho na leitura de mapas e no estímulo à criatividade e autonomia. Estagna-se em uma Geografia Tradicional, desencadeando dificuldades que geralmente se apresentam nas séries 
iniciais do ensino fundamental, e ao invés de serem sanadas, vão se acumulando ao longo da vida escolar. Interrompendo a conexão que deveria ser criada entre o saber cotidiano e o saber acadêmico.

Ainda como sugestão para estudos futuros deve-se desenvolver uma pesquisa que analise propostas de ensino diferenciadas, buscando técnicas que acometam o discente como um todo, ou seja, na interpretação deste material, na prática, na elaboração, pois a ampliação desta visão geográfica poderia facilitar a questão desta alfabetização.

\section{REFERENCIAS}

BRASIL. Secretaria de Educação Fundamental. Parâmetros Curriculares Nacionais: história e geografia. Brasília: MEC/SEF, 1997.

CALLAI, H. C. Aprendendo a ler o mundo: a geografia nos anos iniciais do ensino fundamental. Cad. Cedes, Campinas, v. 25, n. 66, p. 227-247, mai/ago 2005.

CALLAI, H. C. Estudar o lugar para compreender o mundo. In: CASTROGIOVANNI, A. C. (Org.). Ensino de geografia: práticas e textualizações no cotidiano. Porto Alegre: Mediação, 2000.

CAVALCANTI, L.S. Cotidiano, Mediação Pedagógica e Formação de Conceitos: Uma Contribuição de Vygotsky ao Ensino de Geografia. Cad. Cedes, Campinas, vol. 25, n. 66, p. 185-207, maio/ago. 2005.

CASTELLAR, S. M. V. Educação geográfica: a psicogenética e o conhecimento escolar. Cad. Cedes, Campinas, vol. 25, n. 66, p. 209-225, maio/ago. 2005.

CASTELLAR, S. M. V. A cartografia e a construção do conhecimento em contexto escolar. In: ALMEIDA, R. D. (org.) Novos rumos da cartografia escolar: currículo, linguagem e tecnologia. São Paulo: Contexto, 2011.

LACOSTE, Y. A geografia serve antes de mais nada para fazer a guerra. São Paulo: Ática, 1988.

LUNKES, R. P.; MARTINS, G. Alfabetização Cartográfica: um desafio para o ensino de geografia. Disponível em: <http://www.diaadiaeducacao.pr.gov.br/portals/pde/arquivos/10574.pdf>. Acesso em: 01 Ago 2018.

MORAIS, C. C; LASTÓRIA A. C. Cartografia escolar nos anos iniciais: a "alfabetização cartográfica" nas práticas dos professores. ANAIS DO COLÓQUIO DE CARTOGRAFIA PARA CRIANÇAS E ESCOLARES, Vitória, p. 153-165, 2011. 
PASSINI, Elza Yasuko. Alfabetização Cartográfica e o livro didático: uma análise crítica. Belo Horizonte - MG: Editora Lê, 1994.

PENTEADO, H. D. Metodologia do ensino de história e geografia, 2 ed. São Paulo: Cortez, 2008.

RIBEIRO, V.M. Alfabetismo funcional: Referências conceituais e metodológicas para a pesquisa. Revista Educação \& Sociedade, ano XVIII, n. 60, p. 144-158, dezembro/97.

SILVA, L.G. Jogos e situações-problema na construção das noções de lateralidade, referências e localização espacial. In: CASTELLAR, S.M.V. Educação geográfica: teorias e práticas docentes. São Paulo: Contexto, p.137-156, 2006.

SÃO PAULO, Secretaria da Educação. Coordenadoria de Estudos e Normas Pedagógicas. Proposta Curricular para o Ensino de Geografia; $1^{\circ}$ grau. São Paulo, SE/CENP, 1989.

VYGOTSKY, L.S. Pensamento e linguagem. São Paulo: Martins Fontes, 1993. 